\title{
EVALUATION OF FETAL WEIGHT SONOGRAPHICALLY USING AREA OF WHARTON'S JELLY AND MORPHOLOGY OF UMBILICAL CORD
}

\author{
SUSMITA SENAPATI ${ }^{1 *}$, SHASHI SHANKAR BEHERA ${ }^{2}$, PRAFULLA KUMAR CHINARA ${ }^{1}$
}

${ }^{1}$ Department of Anatomy, Institute of Medical Sciences and Sum Hospital, Bhubaneswar, Odisha, India. ${ }^{2}$ Department of Obstetrics and Gynaecology, Kalinga Institute of Medical Sciences, KIIT University, Bhubaneswar, Odisha, India. Email:

\author{
Received: 17 May 2017, Revised and Accepted: 29 June 2017
}

\section{ABSTRACT}

Objective: To establish a sonographic relationship between Area of Wharton's Jelly (AWJ) and umbilical cord morphometry with the birth weight of the fetus in low-risk pregnancies from 13 to 40 weeks.

Methods: A total of 800 singleton pregnant females were subjected for routine sonographic evaluation. The umbilical cord length, diameter, and AWJ were determined. The gestational age and fetal weight were determined using usual fetal parameters. Umbilical cord morphometry along with Area of Wharton Jelly can be utilized as other parameters to increase the accuracy of fetal weight.

Results: In our study, the umbilical cord diameter at birth showed statistically significant positive correlation with birth weight (R=0.167; $<0.001)$. Umbilical cord length, diameter, and Area of Wharton Jelly showed statistically significant positive correlation with birth weight ( $\mathrm{p}<0.001$ ).

Conclusion: Using statistical analysis, a positive correlation was established between estimated fetal weight and fetal age with umbilical cord morphometry and AWJ.

Keywords: Gestational age, Fetal weight, Wharton's Jelly.

(C) 2017 The Authors. Published by Innovare Academic Sciences Pvt Ltd. This is an open access article under the CC BY license (http://creativecommons. org/licenses/by/4. 0/) DOI: http://dx.doi.org/10.22159/ajpcr.2017.v10i10.20037

\section{INTRODUCTION}

The well-being of the fetus is influenced by a number of factors all of which are clearly seen in terms of the birth weight. A low birth weight (LBW) baby is definitely a challenge to the obstetrician and neonatologist. Hence, accurate estimation of fetal weight in antenatal period is helpful in proper management of the pregnant mother and also decreases the associated morbidity [1].

Umbilical cord is connecting cord from developing fetus to placenta. It is derived from allontois and stalk of yolk sac. It is physiological and genetically part of the fetus which conveys the nutrients to fetus from placenta and carries waste products from fetus to placenta. It contains 2 arteries and 1 vein buried in Wharton's Jelly which gives flexibility, mobility, and strength to resist compression at the same time allows the fetus to move freely [1]. Umbilical cord plays an important role in fetal well-being. Several umbilical cord abnormalities are known to cause the adverse prenatal outcome. Abnormal cord length, thick or lean umbilical cords, hyper coiling or hypo coiling, marginal or velamentous insertion of cord may be associated with intrauterine growth restriction, and intrauterine death or fetal distress. Hence, umbilical cord parameters were studied and correlated with fetal parameters.

Studies on the morphological and morphometric characteristic of umbilical cord over the years have found a positive correlation with perinatal outcome and fetal weight [3]. While morphological characteristics such as tensile strength, diameter, umbilical cord circumference, Wharton's Jelly content, umbilical cord length and weight were determined genetically, the umbilical cord development, differentiation, growth and elongation would depend on the sex, nutrient supply, and health status of the fetus [4]. The Wharton's Jelly is one of the major components of the umbilical cord in the $2^{\text {nd }}$ and $3^{\text {rd }}$ trimesters of pregnancy.

In our study, we want to evaluate the accuracy of morphometry of umbilical cord and Area of Wharton's Jelly (AWJ) with relation to birth weight.

\section{MATERIALS AND METHODS}

A prospective cohort clinical study was conducted after Institutional Ethics Committee approval, from January 2013 to December 2015. 800 clinically stable singleton antenatal mothers (aged 18-40 years) from $\left(14^{+0}-39^{+6}\right.$ weeks) attending the antenatal clinic of, Institute of Medical Sciences and Sum Hospital and Kalinga Institute of Medical Sciences Hospital, Bhubaneswar, Odisha, India, in the Department of Obstetrics and Gynaecology subjected for routine ultrasonography between 14 and 40 weeks of gestation were included in the study. Mothers with twin pregnancy, fetus with congenital malformation, fetus with growth retardation, intrauterine death and mothers with medical, and surgical, or obstetric complication associated with pregnancy were excluded from the study.

Normal, healthy, and singleton pregnant woman having accurate knowledge of her last menstrual period and bearing healthy single live fetus was considered as a subject for the above-mentioned study.

Ultrasonography was performed by a single sonologist using a single ultrasound machine to avoid intra observer bias. Area of the umbilical cord was measured along with diameters of all umbilical vessels. AWJ was computed by the formula used below:

$\mathrm{AWJ}=\mathrm{UCA}-(\mathrm{UCV}+\mathrm{UCA} 1+\mathrm{UCA} 2)$

AWJ=Area of Wharton's Jelly

$\mathrm{UCA}=$ Area of umbilical cord

$\mathrm{UCV}=$ Area of umbilical vein

UCA1, UCA2=Area of both the umbilical arteries.

\section{Statistical analysis}

Statistical analysis was performed using Microsoft Excel (2007 version) and the Statistical Package for the Social Sciences (SPSS) version 12. The various statistical tests such as Student t-test was done using 
Microsoft Excel and Pearson's correlations were done using SPSS. All charts were drawn with Microsoft Excel. Statistical significance was defined as $\mathrm{p}<0.05$

\section{OBSERVATIONS AND RESULTS}

Table 1 summarizes distribution of cases according to maternal age. In our study, majority of selected cases were in the age group of 2125 years $(50.50 \%)$ followed by age group $18-20$ years $(38.50 \%)$ and only $3 \%$ were in age group of $>30$ years. The mean age of cases was $22.47 \pm 3.86$ years (range: $18-40$ years)

Table 2 showed the distribution of patients according to trimester of pregnancy. It was observed that in our study majority of patients were from $2^{\text {nd }}$ trimester $(56.50 \%)$ followed by $3^{\text {rd }}$ trimester $(43.50 \%)$. The mean gestational age among patients during pregnancy was 26.16 \pm 6.72 weeks (range: 14 -38 weeks).

Fig. 2 shows that in our study majority of patients were from $2^{\text {nd }}$ trimester $(56.50 \%)$ followed by $3^{\text {rd }}$ trimester $(43.50 \%)$

Table 3 showed the distribution of patients according to umbilical cord diameter. The mean umbilical cord thickness at 14 weeks was $3.73 \pm 0.66 \mathrm{~mm}$ while $21.27 \pm 0.21 \mathrm{~mm}$ at 39 weeks. It shows the thickness of umbilical cord gradually increases as gestational increases.

Fig. 3 shows thickness of umbilical cord gradually increases as gestational increases.

The relation of gestational age and umbilical cord length during pregnancy showed a $\mathrm{R}^{2}=0.999$ and an adjusted $\mathrm{R}^{2}=0.990$. ANOVA analysis showed $\mathrm{F}=3651.701$ and $\mathrm{a} p<0.0001$. This shows a very strong correlation between umbilical cord length and gestational age which was also statistically significant.

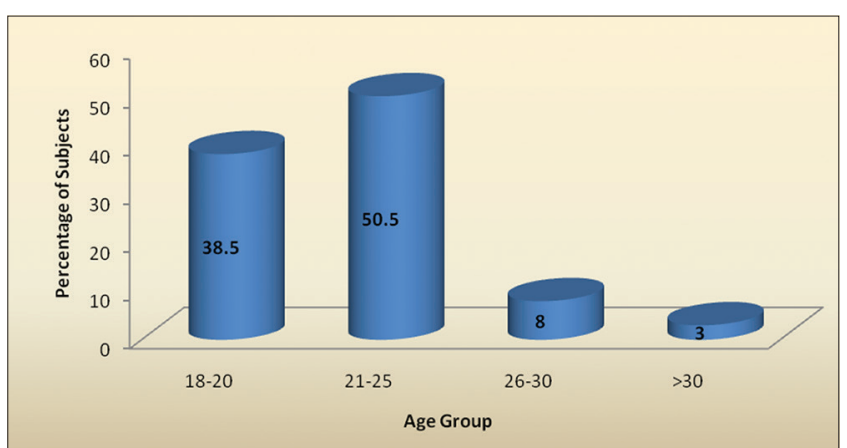

Fig. 1: Age distribution of patients under study

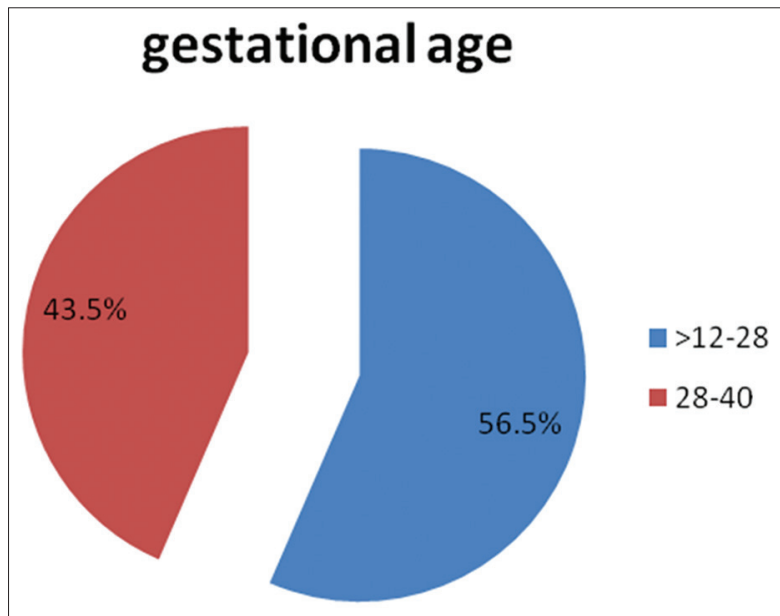

Fig. 2: Distribution of patients as per gestational age
The regression equation for umbilical cord length was $\mathrm{Y}=0.721 \mathrm{x}-6.242$.

Table 4 showed the distribution of patients according to AWJ. The mean AWJ thickness at 14 weeks was $22.50 \pm 0.20 \mathrm{~mm}$ while $141.32 \pm 1.28 \mathrm{~mm}$ at 39 weeks.

The relation of gestational age and AWJ during pregnancy showed a $\mathrm{R}^{2}=0.886$ and an adjusted $\mathrm{R}^{2}=0.881$. ANOVA analysis showed $\mathrm{F}=2413.28$ and $\mathrm{a} p<0.0001$. This shows a very strong correlation between the $\mathrm{AWJ}$ and gestational age which was also statistically significant. The regression equation for Wharton's Jelly area was $Y=5.495 \mathrm{x}-4.11$.

Table 5 described umbilical cord characteristic just after delivery. The mean umbilical cord diameter was $1.20 \pm 0.20 \mathrm{~cm}$; length $54.94 \pm 6.89 \mathrm{~cm}$; and mean Wharton Jelly area was $90.06 \pm 7.92 \mathrm{~mm}$.

The umbilical cord insertion among the majority of subjects was central $(63.50 \%)$ followed by peripheral insertion (35\%) and paracentral (1.50\%).

Table 1: Age distribution of patients under study

\begin{tabular}{llll}
\hline $\begin{array}{l}\text { Age } \\
\text { group (years) }\end{array}$ & $\begin{array}{l}\text { Number of } \\
\text { patients }\end{array}$ & Percentage & Mean age (years) \\
\hline $18-20$ & 308 & 38.50 & $22.47 \pm 3.86$ \\
$21-25$ & 404 & 50.50 & \\
$26-30$ & 64 & 8.00 & \\
$\geq 30$ & 24 & 3.00 & \\
Total & 800 & 100 & \\
\hline
\end{tabular}

Table 2: Distribution of patients as per gestational age

\begin{tabular}{llll}
\hline $\begin{array}{l}\text { Gestational } \\
\text { age (weeks) }\end{array}$ & Number of patients & Percentage & Mean GA \\
\hline$>12-28$ & 452 & 56.50 & $26.16 \pm 6.72$ \\
$28-40$ & 348 & 43.50 & \\
\hline
\end{tabular}

Table 3: Distribution of umbilical cord diameter in as per gestational age in our study

\begin{tabular}{|c|c|c|c|}
\hline Gestational age & Number of patients & $\begin{array}{l}\text { Umbilical cord } \\
\text { diameter }\end{array}$ & SD \\
\hline 14 & 08 & 3.73 & 0.66 \\
\hline 15 & 12 & 4.25 & 0.41 \\
\hline 16 & 28 & 5.30 & 0.22 \\
\hline 17 & 28 & 5.98 & 0.21 \\
\hline 18 & 56 & 6.86 & 0.24 \\
\hline 19 & 24 & 7.43 & 0.19 \\
\hline 20 & 28 & 8.14 & 0.18 \\
\hline 21 & 28 & 8.83 & 0.20 \\
\hline 22 & 52 & 9.65 & 0.31 \\
\hline 23 & 36 & 10.33 & 0.28 \\
\hline 24 & 44 & 11.05 & 0.21 \\
\hline 25 & 24 & 11.69 & 0.42 \\
\hline 26 & 24 & 12.61 & 0.34 \\
\hline 27 & 24 & 13.27 & 0.26 \\
\hline 28 & 36 & 14.21 & 0.31 \\
\hline 29 & 28 & 14.77 & 0.34 \\
\hline 30 & 40 & 15.88 & 0.28 \\
\hline 31 & 36 & 16.16 & 0.41 \\
\hline 32 & 32 & 16.87 & 0.61 \\
\hline 33 & 44 & 17.70 & 0.54 \\
\hline 34 & 36 & 18.36 & 0.62 \\
\hline 35 & 60 & 19.02 & 0.42 \\
\hline 36 & 36 & 19.70 & 0.51 \\
\hline 37 & 24 & 20.53 & 0.43 \\
\hline 38 & 08 & 20.87 & 0.37 \\
\hline 39 & 04 & 21.27 & 0.21 \\
\hline
\end{tabular}


The distribution of neonates according to birth weight showed that among 800 neonates, $404(50.50 \%)$ neonates were having a weight between 2000 and 2500 g. $56(7 \%)$ neonates had weight $<2000 \mathrm{~g}$ while $340(42.50 \%)$ neonates were having weight $>2500 \mathrm{~g}$ (Table 6)

The distribution of neonates according to birth weight showed that neonates having a weight between 2000 and $2500 \mathrm{~g}$ were the majority in our study (Fig. 5)

Table 7 described the correlation between birth weight and umbilical cord characteristics. It was observed that umbilical cord length, diameter, and Area of Wharton Jelly showed statistically significant positive correlation with birth weight $(\mathrm{p}<0.001)$.

Fig. 6 summarizes correlation between birth weight and umbilical cord length. It was observed that umbilical cord length at birth showed statistically significant positive correlation with birth weight $(\mathrm{R}=0.112$; $\mathrm{p}<0.001$ )

Table 4: Distribution of AWJ as per gestational age in our study

\begin{tabular}{llll}
\hline Gestational age & Number of patients & AWJ & SD \\
\hline 14 & 08 & 22.50 & 0.20 \\
15 & 12 & 21.67 & 2.08 \\
16 & 28 & 28.57 & 4.35 \\
17 & 28 & 35.85 & 3.89 \\
18 & 56 & 41.92 & 1.89 \\
19 & 24 & 44.83 & 1.47 \\
20 & 28 & 67.14 & 1.34 \\
21 & 28 & 69.83 & 1.67 \\
22 & 52 & 79.38 & 2.75 \\
23 & 36 & 86.22 & 5.54 \\
24 & 44 & 95.36 & 2.37 \\
25 & 24 & 113.50 & 2.34 \\
26 & 24 & 115.83 & 2.22 \\
27 & 24 & 120.16 & 1.47 \\
28 & 36 & 128.77 & 5.51 \\
29 & 28 & 134.42 & 1.98 \\
30 & 40 & 137.80 & 2.09 \\
31 & 36 & 141.55 & 2.12 \\
32 & 32 & 142.12 & 1.55 \\
33 & 44 & 141.81 & 1.47 \\
34 & 36 & 141.11 & 1.45 \\
35 & 60 & 140.86 & 1.95 \\
36 & 36 & 142.44 & 1.23 \\
37 & 24 & 138.33 & 2.18 \\
38 & 08 & 139.67 & 1.37 \\
39 & 04 & 141.32 & 1.28 \\
\hline $505 t a n$ & &
\end{tabular}

SD: Standard deviation, AWJ: Area of Wharton's Jelly

Table 5: Characteristics of umbilical cord just after delivery

\begin{tabular}{ll}
\hline Umbilical cord characteristic & Mean \pm 2SD \\
\hline Length $(\mathrm{cm})$ & $54.94 \pm 6.89$ \\
Diameter $(\mathrm{cm})$ & $01.20 \pm 00.20$ \\
Wharton jelly area $(\mathrm{mm})$ & $90.06 \pm 7.92$ \\
Cord Insertion $(\mathrm{n}=800)(\%)$ & \\
$\quad$ Central & $508(63.50)$ \\
Peripheral & $280(35.00)$ \\
Paracentral & $12(01.50)$ \\
\hline
\end{tabular}

SD: Standard deviation

Table 6: Distribution of neonates according to birth weight

\begin{tabular}{ll}
\hline Birth weight (g) & Number of neonates (\%) \\
\hline$<2000$ & $56(07.00)$ \\
$2000-2500$ & $404(50.50)$ \\
$>2500$ & $340(42.50)$ \\
Total & $800(100)$ \\
\hline
\end{tabular}

Fig. 7 summarizes correlation between birth weight and umbilical cord diameter. It was observed that umbilical cord diameter at birth showed statistically significant positive correlation with birth weight $(\mathrm{R}=0.167$; $\mathrm{p}<0.001)$.

Fig. 8 summarizes correlation between birth weight and Wharton's Jelly area. It was observed that Wharton's Jelly area at birth showed statistically significant positive correlation with birth weight $(R=0.214$; $\mathrm{p}<0.001$ ).

It was observed that umbilical cord length, diameter, and Wharton Jelly area were significantly lower in LBW as compared to normal weight neonates $(\mathrm{p}<0.05)$.

\section{DISCUSSION}

The present longitudinal study conducted to evaluate the accuracy of fetal weight from the measurement of umbilical cord morphometry

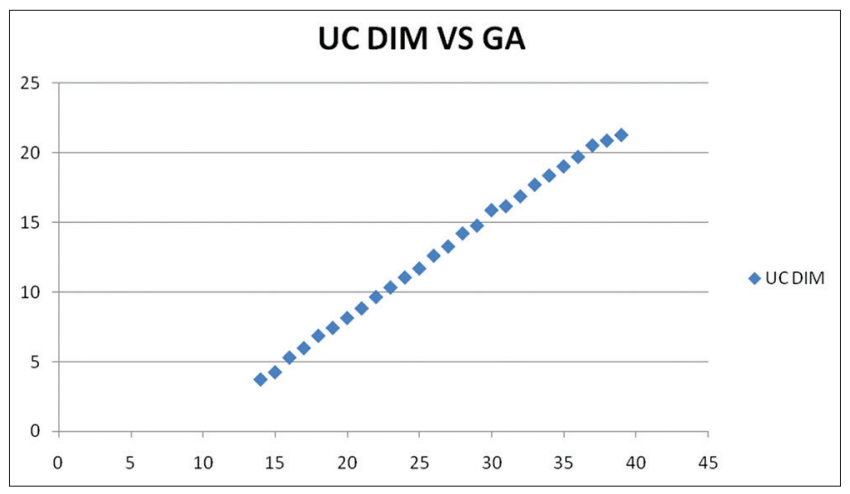

Fig. 3: Distribution of umbilical cord diameter in as per gestational age in our study

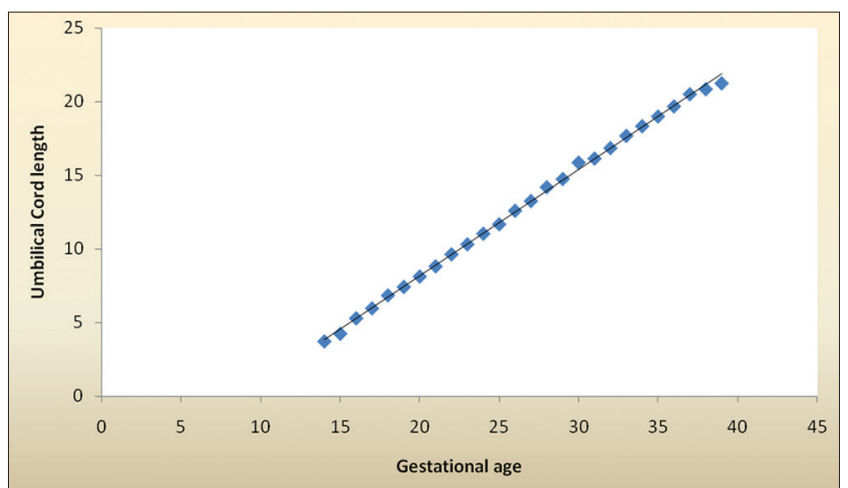

Fig. 4: Relationship between gestational age and umbilical cord length

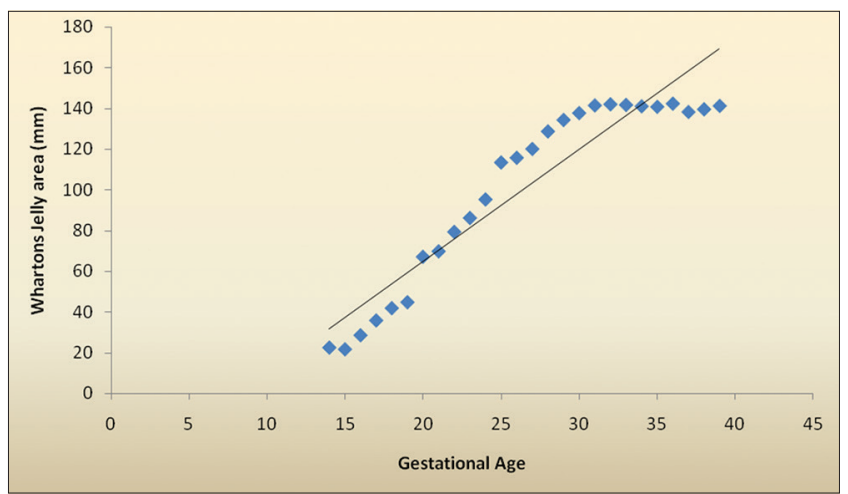

Fig. 5: Correlation of gestational age and Wharton's Jelly area 
Table 7: Correlation of birth weight and umbilical cord characteristics after birth

\begin{tabular}{lll}
\hline Correlation of birth weight & R value & p value \\
\hline Umbilical cord length & 0.112 & $<0.001^{*}$ \\
Umbilical cord diameter & 0.167 & $<0.001^{*}$ \\
AWJ & 0.214 & $<0.001^{*}$ \\
\hline
\end{tabular}

${ }^{*} \mathrm{p}<0.05$ statistically significant, AWJ: Area of Wharton's Jelly

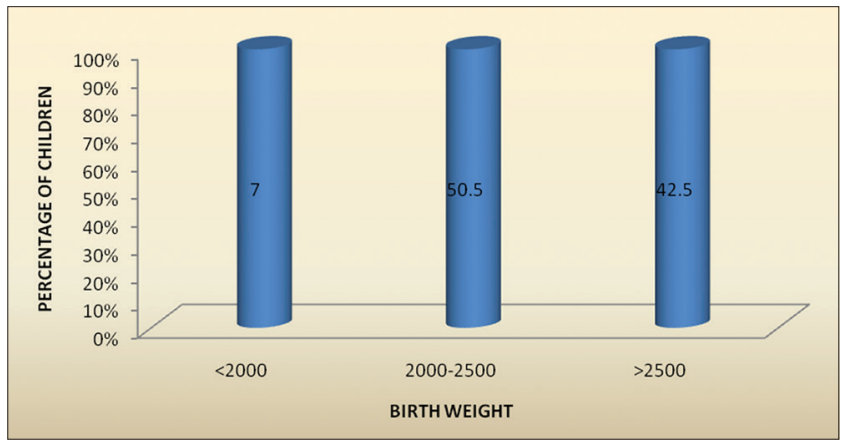

Fig. 6: Distribution of neonates according to birth weight

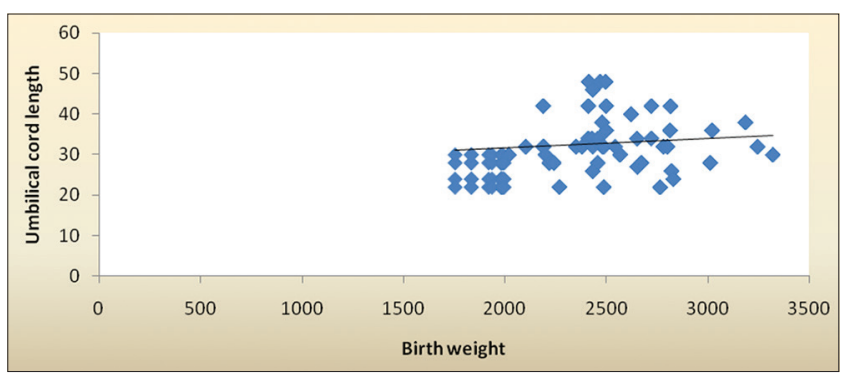

Fig. 7: Correlation of birth weight and umbilical cord length

and AWJ by ultrasound. The effect of umbilical cord length on fetal development has been analyzed by many researchers. It was reported that there was a positive correlation between umbilical cord length and fetal weight.

The study was conducted during the period of January 2013-December 2015. A total sample size of 800 subjects was enrolled in the study.

In this study, majority of selected cases were in the age group of 2125 years $(50.50 \%)$ followed by age group $18-20$ years $(38.50 \%)$ and least were in age group of $>30$ years (03\%). The mean age of cases was $22.47 \pm 3.86$ years (range: $18-40$ years). Among 800 patients majority of patients were from gestational age 35 weeks $(7.5 \%)$ followed by 18 weeks (7\%).

The length of the umbilical cord varies from no cord (achordia) to $300 \mathrm{~cm}$, with diameters up to $3 \mathrm{~cm}$ (Valsamakis et al., 2006). At term, the typical umbilical cord is $55-60 \mathrm{~cm}$ in length, with a diameter of 2.0$2.5 \mathrm{~cm}$ (Yetter, 1998). About 5\% of cords are shorter than $35 \mathrm{~cm}$, and another $5 \%$ are longer than $80 \mathrm{~cm}$ (Berg and Rayburn, 1995). Although it is not fully understood what controls cord length; various authors correlate cord length with fetal activity and movement. It is suggested that sufficient space in the amniotic cavity for movement and the tensile force applied to the umbilical cord during fetal movements are two main factors that determine cord length (Benirschke, 2004). In investigating the clinical significance of umbilical cord length in human pregnancies, Wu et al. (1996) found out that cord length was significantly related to birth weight. They, however, found out that the umbilical cord length does not significantly correlate with maternal age, gestational age, parity, fetal outcome, or intrauterine fetal well-being.

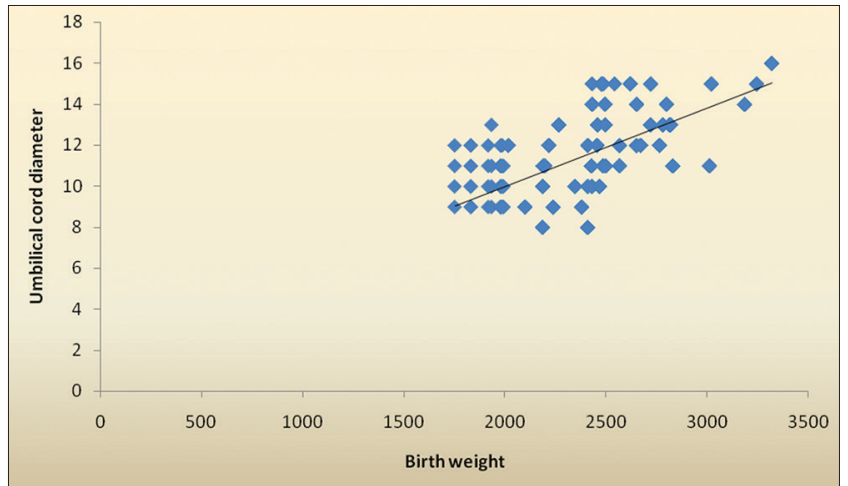

Fig. 8: Correlation of birth weight and umbilical cord diameter

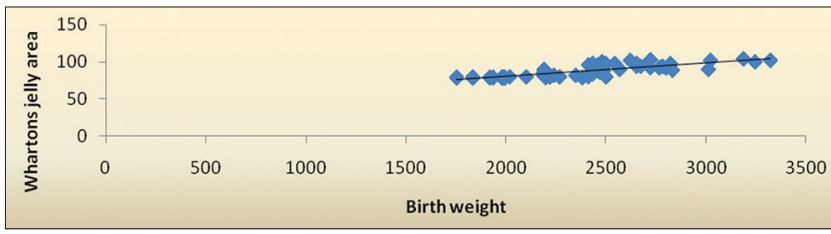

Fig. 9: Correlation of birth weight and Wharton's Jelly area

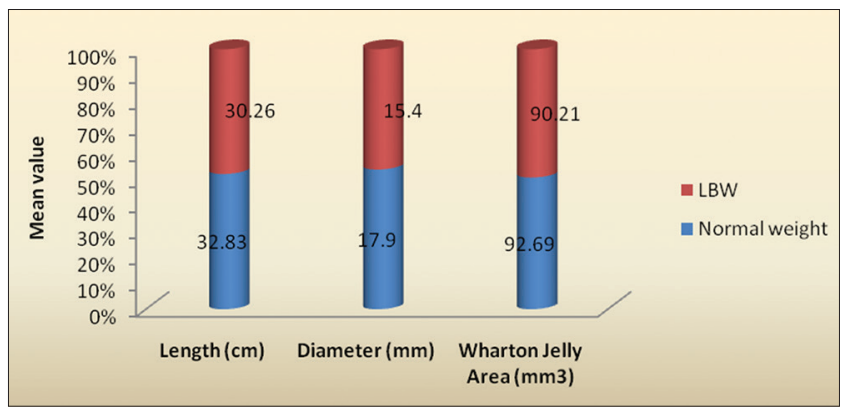

Fig. 10: Comparison of umbilical cord morphology in normal and low birth weight neonates

In our study, Table 3 showed the mean umbilical cord thickness varies from at 14 weeks was $3.73 \pm 0.66 \mathrm{~mm}$ while $21.27 \pm 0.21 \mathrm{~mm}$ at 39 weeks.

The relation of gestational age and umbilical cord length during pregnancy in our study as showed in Fig. 5 was very strong. The correlation between umbilical cord length and gestational age was also statistically significant.

The mean AWJ thickness at 14 weeks was $22.50 \pm 0.20 \mathrm{~mm}$ while $141.32 \pm 1.28 \mathrm{~mm}$ at 39 weeks.

The relation of gestational age and AWJ during pregnancy showed a very strong correlation between the AWJ and gestational age which was also statistically significant. The regression equation for Wharton's Jelly area was $\mathrm{Y}=5.495 \mathrm{x}-4.11$.

Similar findings were seen in a study conducted by Barbieri et al. [11] where the AWJ increased according to gestational age $\left(R^{2}=0.64\right)$, stabilizing from the $32^{\text {nd }}$ week onward. There was a significant linear correlation between AWJ and EFW up to 26 weeks ( $R=0.782)$, and after that, it remained practically constant $(\mathrm{R}=0.047)$. The AWJ increases according to gestational age, with a trend to stabilize at around 32 weeks of gestation. It is also linearly correlated with EFW only up to 26 weeks of gestation.

In this study; the mean umbilical cord diameter was $1.20 \pm 0.20 \mathrm{~cm}$; length $54.94 \pm 6.89 \mathrm{~cm}$; and mean Wharton Jelly area was $90.06 \pm 7.92 \mathrm{~mm}$. 
The findings of the present study were in accordance with a study conducted by Islam [10]; the mean umbilical cord diameter was $1.22 \pm 0.24 \mathrm{~cm}$; length $30.81 \pm 11.79 \mathrm{~cm}$; and mean Wharton Jelly area was $95.18 \pm 9.12 \mathrm{~mm}$.

It was observed that umbilical cord length, diameter, and Area of Wharton Jelly showed statistically significant positive correlation with birth weight $(\mathrm{p}<0.001)$. It was observed that umbilical cord length at birth showed statistically significant positive correlation with birth weight $(\mathrm{R}=0.112 ; \mathrm{p}<0.001)$

Similar findings were seen in a study conducted by Petekkaya et al. [12] where there was a significant positive correlation between umbilical cord and birth weight.

In our study from Fig. 9, it was observed that umbilical cord length, diameter, and Wharton Jelly area were significantly lower in LBW as compared to normal weight neonates $(\mathrm{p}<0.05)$

\section{CONCLUSION}

The present longitudinal study was conducted to evaluate the accuracy of fetal weight from the measurement of umbilical cord morphometry and AWJ by ultrasonography. Correlation of cord parameters with perinatal outcomes suggests that antenatal detection of umbilical cord abnormalities may be useful in the detection of fetuses at risk of cord related complications

There was a significant difference between the intrauterine ultrasonographic measurements and the gross anatomical measurements, therefore, intrauterine ultrasonography may be used as a preliminary guide for the determination of fetal well-being.

\section{REFERENCES}

1. Masuda M, Tohno S, Tohno Y, Minami T, Moriwake Y, Yamada M, et al. Element content of human umbilical artery and vein in umbilical cord. Biol Trace Elem Res 1999;69(3):235-40.

2. Baergen RN, Malicki D, Behling C, Benirschke K. Morbidity, mortality and placental pathology in excessively long umbilical cords: Retrospective study. Pediatr Dev Pathol 2001;4:144-53.

3. Goynumer G, Ozdemir A, Wetherilt L, Durukan B, Yayla M. Umbilical cord thickness in the first and early second trimesters and perinatal outcome. J Perinat Med 2008;36(6):523-6.

4. Collins JH. Umbilical cord accidents: Human studies. Semin Perinatol 2002;26(1):79-82.

5. Standring S. Gray's Anatomy: The Anatomical Basis of Clinical Practice. $40^{\text {th }}$ ed. London, UK: Churchill Livingstone, Elsevier; 2008. p. 176-7, 1302 .

6. Carter AM, Mess A. Evolution of the placenta in Eutherian mammals. Placenta 2007;28(4):259-62.

7. Lyall F, Kaufmann P. In: Kingdom J, Baker P, editors. The Uteroplacental Circulation: Extravillous Trophoblast in Intrauterine Growth Restriction Aetiology and Management. Ch. 6. London: Springer; 2000. p. 89-129.

8. Rossant J, Cross JC. Placental development: Lessons from mouse mutants. Nat Rev Genet 2001;2(7):538-48

9. Wildman DE, Chen C, Erez O, Grossman LI, Goodman M, Romero R. Evolution of the mammalian placenta revealed by phylogenetic analysis. Proc Natl Acad Sci USA 2006;103:3203-8.

10. Islam M. Morphometry of the placenta and umbilical cord in hypertensive Tripuri population. J Evol Med Dent Sci 2013;2(33):6322-7.

11. Barbieri C, Cecatti JG, Surita FG, Marussi EF, Costa JV. Sonographic measurement of the umbilical cord area and the diameters of its vessels during pregnancy. J Obstet Gynaecol 2012;32(3):230-6.

12. Petekkaya E, Deniz M, Yildiz E. Analysis of the relationship between umbilical cord placental morphology and anthropometric measurements of the new-born. Pak J Med Sci 2011;27(3):569-73. 